only discrepancy in this interpretation is the fact that Carus recorded Cynthia rustica $(=S$. grossularia) as well as T. sylvani from the Scilly Islands. Presumably the former term was restricted to the less crowded clusters in which the larvæ had not fixed themselves to the bodies of their parents.

WaLter Garstang.

\section{PRINCIPLES OF BREEDING.}

Principles of Breeding. A Treatise on Thremmatology. By E. Davenport, with appendix by H. L. Rietz. Pp. xiii +727 . Country Life Education Series. (Boston, New York, Chicago, London : Ginn and Company, n.d.) Price 12s. $6 d$.

THIS is the first serious attempt to present a breeding (or, as the author prefers to call it, thremmatology) to English-speaking agricultural students, in which recognition is accorded to much of the recent work done on genetics and some other branches of the physiology of the generative system, and in which effort is made to show the essential value of that work to breeders. The book is most welcome, and our thanks are due for it to the professor of thremmatology in the University of Illinois.

The author's idea of what is needful for the education of an agricultural student is very far in advance of what is usually considered sufficient for that purpose; his book is adapted not only to convey a much wider knowledge of scientific work than has been hitherto thought necessary, but to demonstrate the direct effect such work must have on the fortunes, the ultimate success, of the modern practical breeder.

In spite of the fact that Prof. Davenport declares the breeder of the future will be a book-keeper and statistician, his book shows he has a somewhat wider appreciation of the breeder's qualifications than these words indicate. At the same time, it does seem possible that his enthusiasm for the pure science of genetics has led him to load his book somewhat too heavily with figures, and to neglect to inculcate with sufficient force the necessity for a breeder's close attention to and intimate knowledge of the capacities and peculiarities of individual members of a flock or herd. This is, in our opinion, a serious defect in a text-book for agricultural students; the power of close observation is an essential qualification for a breeder.

Similarly, the author's endeavour to induce the student to take " short cuts" to success is to be deprecated. He urges "A man must realise the fruit of his own labours." "The breeder must therefore work faster than nature." The " evolutionary principle" must be accelerated; and so forth. In so far as it is possible to gain these ends his attempts to further them are good, but he omits to point out that at the best these ends can be only partially gained, and that the evolutionary principle cannot be accelerated sufficiently to satisfy individual aims. He notes that "experience shows that the purposes, standards, and methods of a successful breeder are seldom handed down from one man to another," but he does not attempt to point out the means whereby this can be obviated, and yet it is the most severe handicap to progress which breeders suffer from.

There is one great opportunity which all professors of a big agricultural college have to their hand, that of organising a system of records of the practical results subsequently gained by all the students which pass through their schools. Such records, compiled by men trained by modern scientific methods and made available for use at their college, would be of incalculable value, both to the professors and the breeders of future generations; in order to carry out such a scheme, however, the student must be taught to understand that there are no short cuts to knowledge, and that the only way they can hope to accelerate the acquisition of knowledge of evolutionary principles is by pooling their experiences, their failures as well as their successes.

Part i., on variation-the author makes variation rather than heredity the initial leading thought of his scheme, putting the cart before the horse and thereby somewhat confusing the issue-is a brief résumé of some of the leading features of that branch of the subject, instances being given of a kind specially suitable to stimulate the interest of American students, for whom the book is written.

Part ii., on the causes of variation and the relative stability of living matter, and part iii., on transmission, constitute the bulk of the book. The author's clear and forcible writing, the thoroughness of his treatment, the arrangement of his facts, and the wealth of illustration he gives are worthy of great praise. These sections are not only a valuable summary of what is known, but contain much original thought, and deserve the attention of all students of the subject.

Part iv. is on practical problems. Those dealt with under the headings selection, systems of breeding, plant breeding, and animal breeding are full of good common sense and sound advice; any breeder would do well to consult them.

Thus if it has failings the book has great merit, and it is to be hoped the example set by Prof. Davenport will be followed in this country, where the education of agricultural students in the science of breeding is sadly behindhand.

\section{THERMOCHEMISTRY.}

Thermochemistry. By Julius Thomsen; translated from the Danish by Katharine A. Burke. Pp. $\mathrm{xv}+495$. (London: Longmans, Green and Co., rgo8.). Price $9 s$.

WING to the rapid strides which have recently been made in physical chemistry, the subject of thermochemistry, which is itself of a physical nature. has been rather left in the background. At one time it was hoped that thermochemistry would be of very great help in elucidating the hidden laws governing chemical reactions, but unfortunately it has hardly realised expectations.

Although a very large amount of work has been done upon this subject, we can hardly say that it has been found possible to rely upon thermochemical methods 